\title{
Effects of Gas Channel Design on Water Management and on the Performance of Polymer Electrolyte Membrane Fuel Cells: A Review
}

\author{
Thi Diep Tran ${ }^{1,2}$, Shoudao Huang ${ }^{1}$, Duc Ha Vu ${ }^{1,2}$, Vinh Nguyen Duy ${ }^{3,4, *}$ \\ ${ }^{1}$ College of Electrical and Information Engineering, Hunan University, Hunan, P.R. China \\ ${ }^{2}$ Faculty of Electrical Engineering, Sao Do University, Hai Duong, Vietnam \\ ${ }^{3}$ Department for Management of Science and Technology Development, Ton Duc Thang University, \\ Ho Chi Minh City, Vietnam \\ ${ }^{4}$ Faculty of Electrical \& Electronics Engineering, Ton Duc Thang University, Ho Chi Minh City, \\ Vietnam \\ *E-mail: nguyenduyvinh@tdt.edu.vn
}

doi: $10.20964 / 2018.11 .22$

Received: 14 June 2018 / Accepted: 18 July 2018 / Published: 1 October 2018

\begin{abstract}
Recently, polymer electrolyte membrane fuel cells (PEMFCs) have been studied by scientists worldwide as tools that can replace traditional energy sources to address issues related to energy depletion and environmental pollution. PEMFCs present many advantages for various applications, such as their high efficiency, ability to self-start at low temperatures and clean emissions. However, PEMFCs have not yet been widely used in applications due to their high manufacturing costs and low levels of power density. Flow-field design optimization serves as a good means to enhance fuel cell operations; as a result, many studies have focused on optimizing the flow field to improve water management and fuel cell performance output. The paper provides a review of a variety of studies conducted on flow-field configuration design that contribute greatly to water management and fuel cell operation. Regarding pin-type flow fields, the design uses several pins of various shapes arranged in a rectangular or spherical configuration. The membrane can become dry as a result of over water discharge. Meanwhile, for straight and parallel configurations, such designs include many separate parallel flow channels that connect the inlet to the outlet. These designs are simple and require the lowest level of pressure drop by equally distributing gases into parallel paths. Some works have designed bipolar plate configurations that include multi-pass serpentine flow fields, which enhance under-rib convection, generate a more uniform gas distribution, and quickly remove water from underrib regions. A geometrical characterization shows that multi-pass serpentine flow fields strengthen under-rib convection intensities and support more uniform conditions in terms of gas concentrations, temperatures, and pressure levels in comparison to conventional serpentine flow fields.
\end{abstract}


Keywords: Polymer electrolyte membrane fuel cell; Flow-field design; Under-rib convection; Diffusion, Water management; Polarization performance

\section{$\underline{\text { FULL TEXT }}$}

(C) 2018 The Authors. Published by ESG (www.electrochemsci.org). This article is an open access article distributed under the terms and conditions of the Creative Commons Attribution license (http://creativecommons.org/licenses/by/4.0/). 